\title{
Experiência exitosa: grupo de caminhada da Unidade Básica de Saúde São Sebastião - Viçosa, Minas Gerais
}

\author{
Isabelle Abranches da Silva, Angélica Souza Andrade
}

\begin{abstract}
Resumo
A atividade física, realizada com regularidade, é uma das principais bases para a manutenção da saúde, em qualquer idade. Ela se torna ainda mais importante para os idosos. Isto porque quando envelhecemos, o corpo sofre algumas transformações como: perda da força muscular, diminuição da flexibilidade, da coordenação e torna-se mais propício ao desenvolvimento de algumas doenças crônicas não transmissíveis. Todas estas alterações fazem parte do processo natural do envelhecimento, mas podem ser amenizadas através da prática regular da atividade física. É nessa perspectiva que encaminhamos nosso trabalho, no sentido de compreender a fim de amenizar os problemas inerentes não somente a esse público alvo, mas da comunidade em geral, promovendo momentos de prazer e descontração através das práticas corporais, proporcionando melhorias na qualidade de vida dos envolvidos. O Grupo de Caminhada vem de encontro com as necessidades deste grupo etário e constitui-se numa parceria do Núcleo de Apoio Saúde da Família (NASF) e a equipe Estratégia Saúde da Família (ESF) São Sebastião, para ofertar práticas corporais em prol da melhoria da qualidade de vida, colaborar com a inclusão social, bem estar físico, promoção da saúde dos mesmos (iniciou-se em junho de 2015 e encontra em desenvolvimento até o momento). O grupo acontece todas as terças e quintas-feiras às 7 horas da manhã, saindo do PSF São Sebastião (Vale do Sol) em direção à estrada das Coelhas e conta com a participação de aproximadamente 20 usuários. Em primeira instância todos os interessados em participar do grupo passaram por uma consulta médica, para que assim fossem avaliados se estavam aptos ou não para a prática de atividade física. Antes de iniciarmos a caminhada é aferida a pressão de todos participantes e glicemia dos diabéticos pelo técnico de enfermagem, e em caso de alteração das mesmas, é aconselhado a não participação da atividade, porém, há um "termo de responsabilidade" que o usuário assina se responsabilizando por eventuais conseqüências. A caminhada orientada tem duração de 40 a 50 minutos e voltando o trajeto da caminhada paramos em um lugar específico (mais ou menos no meio do trajeto), onde são realizadas as atividades ao ar livre. O grupo conta com a orientação da Profissional de Educação Física da equipe do NASF e o apoio dos demais profissionais da equipe multidisciplinar do NASF (psicóloga, assistente social, nutricionista, farmacêutica e fisioterapeuta), dos Agentes Comunitários de Saúde, do técnico de enfermagem e da enfermeira responsável pela unidade. Durante o Grupo de Caminhada são desenvolvidas atividades de alongamentos e relaxamento, dinâmicas relacionadas a diferentes temas (autoestima, motivação, ansiedade, estresse), orientações e pequenas palestras que abordam temas relacionados à saúde e bem estar (medicamentos, hipertensão, diabetes mellitus). $\mathrm{O}$ trabalho desenvolvido com o Grupo de Caminhada trouxe mais autonomia, fortalecimento de vínculos, socialização, melhoria da autoestima e socialização, melhoria das capacidades físicas, enfim, nos proporcionou uma troca de experiências enriquecedora. Contudo, é de extrema importância que a atividade física faça parte dos hábitos de vida de qualquer indivíduo, pois é essencial para uma melhor qualidade de vida.
\end{abstract}

Descritores: Grupo de Caminhada; Atividade Física, Qualidade de Vida 